\title{
A CONSTRUÇÃ̃O DE INDICADORES DE EMANCIPAÇÃO NA METODOLOGIA DE PESQUISA QUALITATIVA EM EDUCAÇÃO
}

\author{
Telmo Adams ${ }^{1}$ \\ Caroline Lisian Gasparoni ${ }^{2}$
}

\begin{abstract}
Resumo
O artigo, resultante de uma pesquisa no campo da Educação Não Escolar, narra o caminho metodológico percorrido na elaboração de indicadores qualitativos de emancipação, que orientaram a análise da experiência de educação profissionalizante realizada por uma ONG com jovens de periferia urbana. Reflete-se sobre questões relativas à pesquisa qualitativa em educação, com base no método da fenomenologia existencial, a partir das contribuições de Merleau-Ponty e Paulo Freire. A operacionalização metodológica viabilizou-se por meio da observação participante, análise documental, entrevistas individuais e interações coletivas. Conclui-se que, a partir da relação entre teoria e campo empírico, a construção de indicadores de emancipação possibilitou um processo interpretativo que contribuiu efetivamente na compreensão do fenômeno estudado, constituindo-se um instrumento válido para a pesquisa qualitativa em educação.
\end{abstract}

Palavras-chave: Pesquisa qualitativa; Indicadores de emancipação; Metodologia de pesquisa; Organizações não governamentais

\section{CONSTRUCTION OF EMANCIPATION INDICATORS IN QUALITATIVE RESEARCH METHODOLOGY IN EDUCATION}

\begin{abstract}
${ }^{1}$ Professor e pesquisador, doutor em educação, PPGEdu da Universidade do Vale do Rio dos Sinos - Unisinos. RS. E-mail: adams.telmo@gmail.com

2 Professora, mestre em educação, Prefeitura Municipal de São Leopoldo/RS. E-mail: carolggasparoni@gmail.com.
\end{abstract}


The article, resulting from a research in the field of Non Schooling Education, describes the methodological path followed in the development of emancipation qualitative indicators, which guided the analysis of professional education experience conducted by an ONG with young urban periphery. It reflects on issues relating to qualitative research in education, based on the method of existential phenomenology, from the contributions of Merleau-Ponty and Paulo Freire. The methodological operation was made possible by means of participant observation, document analysis, personal interviews and collective interactions. We conclude that, from the relationship between theory and empirical field, construction of emancipation indicators allowed an interpretive process which contributed effectively in understanding the phenomenon studied, becoming a valid instrument for qualitative research in education.

Keywords: Qualitative research; Emancipation indicators; Research methodology; Non government organizations

\section{LA CONSTRUCCIÓN DE INDICADORES DE EMANCIPACIÓN EM LA METODOLOGÍA DE INVESTIGACIÓN CUALITATIVA EN EDUCACIÓN}

\section{Resumen}

El artículo, como resultado de una investigación en el campo de la Educación No Escolar, describe la ruta metodológica utilizada en la elaboración de indicadores cualitativos de emancipación, que guiaron el análisis de la experiencia de formación profesional realizado por una ONG con jóvenes de periferia urbana. Reflexiona sobre las cuestiones relacionadas con la investigación cualitativa en educación, basado en el método de la fenomenología existencial, a partir de las contribuciones de Merleau-Ponty y Paulo Freire. La operación metodológica fue posible por medio de la observación participante, análisis de documentos, entrevistas personales e interacciones colectivas. Llegamos a la conclusión de que, a partir de la relación entre la teoría y campo empírico, la construcción de indicadores de emancipación permitió un proceso interpretativo que contribuyó eficazmente en la comprensión del fenómeno estudiado, convirtiéndose en un instrumento válido para la investigación cualitativa en educación. 
Palabras-clave: Investigatión cualitativa. Indicadores de emancipación. Metodología de investigación. Organizaciones no governamentales.

\section{INTRODUÇÃO}

As pesquisas desenvolvidas em Ciências Humanas, em especial as da educação, possuem, em sua maioria, o enfoque qualitativo no que se refere ao conjunto organizacional de modos e procedimentos de realização e produção de conhecimento. No que tange a sua metodologia, destaca-se a densidade descritiva e interpretativa (STRECK, 2016). O presente texto trata da construção de indicadores de emancipação como procedimento que contribui para a qualidade da pesquisa, seja no processo de produção de informações no campo empírico e interpretação em uma pesquisa sobre um projeto social e educativo em uma Organização Não Governamental.

O principal objetivo da pesquisa foi compreender o contexto da proposta do projeto social e educativo, a partir dos sentidos a ele atribuídos pela ONG, por um Educador Social responsável e jovens que o frequentavam. A observação participante ocorreu, de modo preponderante, no acompanhamento a uma turma de jovens estudantes de um Curso de Hardware, durante um semestre.

A problemática local envolvendo jovens de periferias urbanas relaciona-se diretamente com o ambiente sócio histórico mais amplo. As organizações da sociedade civil, no transcorrer das últimas décadas, têm mobilizado ações socioeducativas por meio de projetos sociais junto aos mais variados segmentos da sociedade, entre eles, o atendimento a crianças e jovens. $\mathrm{O}$ termo ONG (Organização Não Governamental) tende a estar associado ao chamado 'Terceiro Setor'. De acordo com o Manual do Terceiro Setor (Instituto Pro Bono, 2005), "Trata-se de um agrupamento de pessoas, estruturado sob a forma de uma instituição da sociedade civil, sem finalidades lucrativas, tendo como objetivo comum lutar por causas coletivas e/ou apoiá-las" (p. 13).

No entanto, a ambiguidade da expressão "terceiro setor", como parte da reestruturação capitalista, caracteriza-se pela sua extrema diversidade e interesses contraditórios. A designação inclui, tanto instituições sociais tendencialmente funcionais à lógica das políticas neoliberais de desresponsabilização do Estado frente à questão social, quanto organizações que combatem essa lógica colocando-se na perspectiva da transformação social. Tal como ocorre 
nesse contexto, "o conhecimento e a produção de conhecimento, não se dão em espaços isentos de interesses e nem fora das relações e conflito de poder" (STRECK, 2016, p. 3).

A necessidade de construção de indicadores está relacionada diretamente os sentidos de emancipação utilizado como um dos eixos principais na pesquisa. O conceito de emancipação, nesta pesquisa, foi assumido como formação para o protagonismo dos sujeitos, da sua capacidade criativa de atuar na sociedade de forma autônoma e solidária, visando à superação da opressão, no permanente libertar-se do poder exercido por alguém (STRECK \& ADAMS, 2014). Esse processo, não linear e sempre inacabado, ocorre na interação dialética entre fatores políticos e econômicos micro e macrossociais, sendo que as condições educativas se inserem no contexto sócio histórico que o suscita. Localmente, é possível alcançar aspectos da emancipação, mesmo em um contexto adverso. Ao mesmo tempo, a compreensão da interdependência entre as práticas locais e a realidade social mais ampla constitui-se uma das características da emancipação.

A intencionalidade, inerente ao desenvolvimento de toda pesquisa, incide na produção acadêmica por meio das escolhas teóricas e metodológicas. Assim, ao longo deste artigo, assumimos o método da Fenomenologia Existencial (REZENDE, 1990), ${ }^{3}$ tendo como inspiração a relação que Paulo Freire estabeleceu entre a fenomenologia e a dialética marxista, especialmente, pela compreensão de que os fenômenos são historicamente construídos numa relação dialética entre objetividade/subjetividade.

Na sequência o texto aborda a construção do caminho metodológico, com a aconstrução dos indicadores de emancipação.

\section{A CONSTRUÇÃO DO CAMINHO METODOLÓGICO}

Toda metodologia científica busca encontrar meios de resolver, de modo sistêmico e confiável, os problemas que lhe propõe a exata apreensão do mundo. (LAPERRIÉRE, 2008, p. 410).

Durante muito tempo, as Ciências Humanas buscaram chamar para si os critérios dos métodos quantitativos, procurando minimizar os efeitos da subjetividade e do contexto social. Entretanto, essa estratégia positivista transferida para a pesquisa sobre as relações e o comportamento humano, - característica central da pesquisa qualitativa -, não alcançou bons

\footnotetext{
${ }^{3}$ Antônio Muniz de Rezende é psicanalista, membro efetivo da Sociedade Brasileira de Psicanálise de São Paulo, doutor em Filosofia pela Universidade Católica Louvain Bélgica, professor titular aposentado da UNICAMP. Tem sido uma das referências que contribuiu na ressignificação da fenomenologia no Brasil.
} 
resultados, sendo a causa de uma acentuada artificialidade e limitações decorrentes da transposição deste modelo na pesquisa social. A construção de metodologias qualitativas ampliou-se pela constituição de formas organizadas e sistemáticas de produção de dados que levam em conta a intencionalidade, a (inter)subjetividade e a complexidade das relações entre conhecimento e participação no mundo constituído por múltiplas determinações. O mundo vivido é anterior à ciência que, por sua vez é construída a partir do primeiro. Daí a ênfase de Merleau-Ponty (1999, p. 1), afirmando que:

Todo o universo da ciência é construído sobre o mundo vivido, e se queremos pensar a própria ciência com rigor, apreciar exatamente seu sentido e seu alcance, precisamos primeiramente despertar essa experiência do mundo da qual ela é a expressão segunda.

Se a fenomenologia é o estudo das essências, ela é também uma filosofia que recoloca as essências na existência e compreende o ser humano e o mundo a partir de sua 'facticidade' (MERLEAU-PONTY, 1999). Com base nesse argumento, Rezende (1990) enfatiza a dimensão existencial da fenomenologia desse filósofo, partindo do pressuposto de que o mundo está 'ali' antes da reflexão, como uma presença inalienável: "o mundo é aquilo que nós percebemos" (MERLEAU-PONTY, 1999, p. 14). Do mesmo modo, Freire (1978) insiste que o mundo não existe sem a existência do ser humano que o reconhece. Heidegger (1981) e Merleau-Ponty (1999) foram além do idealismo da consciência pura, assentando as bases na existência humana, articulando, de modo inseparável, objetividade e subjetividade, mas na condição de que o real existe antes de ser descrito. "E porque somos do começo ao fim relação ao mundo que a única maneira, para nós, de apercebermo-nos disso é suspender este movimento, recusar-lhe nossa cumplicidade...” (MERLEAU-PONTY, 1999, p. 10).

Nesse sentido a "admiração" diante do mundo é melhor compreensão de redução. Enfatiza que: "Longe de ser, como se acreditou, a fórmula de uma filosofia idealista, a redução fenomenológica é a fórmula de uma filosofia existencial: o ser-no-mundo ("In-derWelt-Sein") de Heidegger só se manifesta sobre o fundo da redução fenomenológica." (MERLEAUPONTY, 1999, p. 11). Nesta linha a busca da essência do mundo não significa "buscar aquilo que ele é em idéia", mas "buscar aquilo que de fato ele é para nós antes de qualquer tematização" (MERLEAU-PONTY, 1999, p. 13).

E, por último, retomando de Husserl a intencionalidade, insiste que esta compreende uma postura que envolve o corpo, a existência, a experiência (MARLEAU-PONTY, 1999), em que, pelo fato de estarmos no mundo, 'estamos condenados' ao sentido das coisas. 
O mundo fenomenológico é não o ser puro, mas o sentido que transparece na intersecção de minhas experiências, e na intersecção de minhas experiências com aquelas do outro, pela engrenagem de umas nas outras; ele é, portanto, inseparável da subjetividade e da intersubjetividade que formam sua unidade pela retomada de minhas experiências passadas em minhas experiências presentes, da experiência do outro na minha (MERLEAU-PONTY, 1999, p. 18).

O método fenomenológico, na perspectiva existencial, considera a existência de diversos modos de pensar, provenientes de um ou de mais sujeitos inseridos na complexidade do mundo, sendo que, do mesmo modo, a complexidade deste mundo está inserida em cada sujeito (CABRAL, 2014). Incorporando elementos da teoria crítica, Rezende (1990), propõe uma "dialética plurilinear ou polissêmica e continua afirmando a ambiguidade do fenômeno que nunca se reduz a um só de seus aspectos...” (p. 20), recusando o dogmatismo em todas as suas formas.

Com esses elementos indicados, aproximamo-nos de Freire (1976; 1978; 2007), articulando aspectos centrais da fenomenologia com a teoria crítica. Incorpora aspectos do marxismo, entre os quais vale citar os conceitos de ideologia, de alienação, de exploração econômica, de dominação política, a contradição entre opressor e oprimido, a relação entre o fenômeno e o contexto em que ele se engendra, entre outros. Mas, possivelmente, o ponto comum entre os dois autores que mais se destaca seja o da dialética entre objetividade e subjetividade. Em sintonia com Merleau-Ponty assumiu a necessidade de ultrapassar uma compreensão dicotômica como bem enfatizou Fiori (1978) no prefácio do Pedagogia do Oprimido. "Nessa linha de entendimento, reflexão e mundo, subjetividade e objetividade não se separam: opõe-se, implicando-se dialeticamente" (FIORI, 1978, p. 7). E mais adiante Freire conclui: "Nem objetivismo, nem subjetivismo ou psicologismo, mas subjetividade e objetividade em permanente dialeticidade" (FREIRE, 1978, p. 39).

Em Ação Cultural para a liberdade, destaca que

Este processo de orientação dos seres humanos no mundo não pode ser compreendido, de um lado, de um ponto de vista puramente subjetivista; de outro, de um ângulo objetivista mecanicista. Na verdade, esta orientação no mundo só pode ser realmente compreendida na unidade dialética entre subjetividade e objetividade (FREIRE, 2007, p. 51).

Estudioso de Freire e Merleau-Ponty, Passos (2010) faz uma aproximação entre o pensamento dos dois autores afirmando que "Freire não deixava qualquer dúvida: é preciso vencer o divórcio entre o dito e o feito; o pensado e o vivido; o material e o imaterial" (PASSOS, 2010, p. 185). Assim, postulou que consciência e mundo dialogam, formando uma coisa só. 
Afirma a existência como uma relação dialética entre o mundo, minha consciência e a consciência do(s) outro(s), o que revela o veio da fenomenologia em Freire (1976, p. 39):

\begin{abstract}
As relações que o homem trava no mundo com o mundo (pessoais, impessoais, corpóreas e incorpóreas) apresentam uma ordem tal de características que as distinguem totalmente dos puros contatos, típicos da outra esfera animal. Entendemos que, para o homem, o mundo é uma realidade objetiva, independente dele, possível de ser conhecida. É fundamental, contudo, partirmos de que o homem, ser de relações e não só de contatos, não apenas está no mundo, mas com o mundo.
\end{abstract}

Em síntese, tanto para Merleau-Ponty quanto para Freire o mundo não pode ser reduzido à consciência, sendo que os fenômenos estão sempre envolvidos pela subjetividade. São resultantes da construção histórica onde os sujeitos estão embebidos de objetividade. Na Fenomenologia Existencial, a consciência está encarnada no mundo, como uma estrutura, uma unidade dialética entre o SER-HUMANO-NO-MUNDO e o mundo, entre objetividade e subjetividade; um ser humano individual e social constituído socialmente dentro de determinadas condições sócio históricas (REZENDE, 1990), porém, sem estar à mercê das circunstâncias deterministas do mundo objetivo.

\title{
OPERACIONALIZAÇÃO DO PROCESSO METODOLÓGICO
}

Seguindo o caminho do método fenomenológico por meio de diário de campo buscamos descrever o fenômeno de modo denso, tal como ele se apresentava para nós, sem uma definição anterior de categorias ou de um caminho prévio para a sua análise. "Não há uma interpretação que se pauta em uma lógica pré-estabelecida por nós e que utilizamos para incluir nela os dados da realidade" (GIOVEDI, 2006, p. 56). Evidentemente, não se tratou de uma descrição neutra, mas situada, consciência essa que julgamos importante na pesquisa qualitativa, visto que a explicitação das condições é fundamental para a compreensão dos fenômenos em profundidade. Há uma interação sem rupturas entre o mundo pensado e o vivido. Salientamos que, nessa perspectiva, as teorias não são referências únicas para explicar todos os fenômenos, pois elas são produtos de experiências vividas geradoras de sentidos de vida, sem se referir a respostas às situações pesquisadas como verdades universais e absolutas.

A partir das características do campo empírico, das interrogações estabelecidas a seu respeito e das condições pessoais dos pesquisadores para realizar a pesquisa, foram feitas as opções para trilhar o referido caminho metodológico, valorizando sempre as provocações e as inspirações da experiência em foco e seu contexto. 
$\mathrm{Na}$ pesquisa aqui referida, o processo metodológico desenvolveu-se em três passos principais. O primeiro foi o da constatação, por meio da descrição do fenômeno estudado, tal como se manifesta e como foi percebido. Nessa fase "Trata-se de constatar a realidade com um levantamento adequado dos dados, do sentido dado, em vista de uma descrição suficiente e significativa da situação de mundo que foi escolhida como objeto de pesquisa" (REZENDE, 1990, p. 58).

O segundo passo, caracterizou-se pelo processo compreensivo ou interpretativo, por meio da reflexão analítica do fenômeno descrito na etapa anterior, evidenciando "as diversas relações internas e as manifestações de suas contradições bem como a descoberta das possibilidades de auto superação" (REZENDE, 1990, p. 58).

E o terceiro momento, coerente com a perspectiva da pesquisa que se propõe conhecer e, ao mesmo tempo, assumir o caráter prospectivo, onde as conclusões alcançadas acerca do fenômeno estudado podem subsidiar proposições em vista de produzir outra realidade, "outra situação histórica, julgada preferível e desejada pelos sujeitos e para eles" (REZENDE, 1990, p. 58). A interação não linear entre os três passos referidos contribui para superar o risco da reprodução do sistema ao invés de sua transformação.

Ao relacionar o processo de pesquisa com o pensamento de Paulo Freire, encontramos, também, embasamento para a realização de uma investigação mediada pela postura ética, que se preocupa em ouvir e considerar os participantes no processo de pesquisa como coconstrutores de conhecimento. Decorrente desse posicionamento, a formulação do problema de estudo foi impactada pela realidade vivida no contexto sócio histórico do locus da pesquisa. Inspirada nessa mesma perspectiva, a própria elaboração da metodologia somente foi definida após contato inicial com os sujeitos escolhidos.

A partir desses pressupostos, momentos de imersão no campo empírico definido foram realizados durante um período específico, objetivando conhecer as características que compunham o espaço da experiência, para a construção de um conhecimento dos sujeitos, sua sistemática de funcionamento, além de favorecer o encaminhamento das demais técnicas de pesquisa.

No apoio e na sustentação da produção de dados, três técnicas foram valorizadas: observação participante, análise documental e entrevistas (individuais e grupais).

A observação participante assumiu a coerência intencional de contribuir com o campo pesquisado. (BRANDÃO \& STRECK, 2006). O diário de campo foi o instrumento de registro do "olhar", do "ouvir" e, posteriormente, da descrição detalhada do fenômeno. Essa ferramenta 
de rememoração do pesquisador constitui-se como recurso estratégico da memória incapaz de guardar todos os detalhes da observação em si e do que ela suscitou em termos de reflexões, intuições, relações e suspeitas. O diário de campo trouxe ao presente o vivenciado, contribuindo para a construção de suas impressões, descrições e interpretações.

À observação participante, articulamos a análise documental, que buscou encontrar informações referentes ao campo. Foram analisados todos os documentos do projeto educativo e social aos quais tivemos acesso, para agregar informações com o intuito de responder ao problema de pesquisa formulado.

Por último, foram feitas entrevistas individuais e grupais com ex-estudantes do projeto educativo e social, com o Educador Social, com a coordenadora pedagógica, a de projetos e com a diretoria da instituição.

As entrevistas grupais, em forma de oficinas, foram realizadas com jovens estudantes de uma turma do ano de 2014 e de uma turma do ano de 2015. Seu intuito foi o de ampliar e tornar as informações mais densas em termos de sentidos para os participantes.

A realização de oficina permitiu um diálogo coletivo mais livre e lúdico, com uma interação que buscou superar o distanciamento entre o mundo do pesquisador e dos sujeitos participantes. Tal limite, pode ser transposto mediante o estabelecimento de uma relação dialógica em que a qualidade do ouvir é aguçada pela sensibilidade (FREIRE, 1978). Essa relação dialógica é essencial no processo da descrição densa do fenômeno.

No decorrer desse processo deu-se a construção e a análise dos indicadores qualitativos, para compreender o dimensionamento das possibilidades de emancipação dos jovens envolvidos no projeto educativo e social. Assim, registros do diário de campo, entrevistas gravadas e transcritas, juntamente com os destaques dos documentos foram organizados em uma grande tabulação para facilitar o processo compreensivo crítico sobre as informações. Desse modo, gerou-se uma visão mais ampla e real do fenômeno na inter-relação com o contexto.

Na continuidade, descrevemos os indicadores mediadores do processo interpretativo.

\section{INDICADORES QUALITATIVOS DE EMANCIPAÇÃO}

A construção dos indicadores qualitativos insere-se no contexto da necessidade de um olhar compreensivo sob diferentes perspectivas a respeito do fenômeno a partir do que foi possível captar do campo empírico, considerando o foco teórico-metodológico escolhido. Os 
indicadores foram se constituindo como uma mediação para o observar, o descrever, o interpretar e, ao mesmo tempo, para vislumbrar possíveis proposições, tanto para a experiência analisada, como para o campo da educação não escolar (GASPARONI, 2015). Dessa forma, a partir da reflexão sobre o fenômeno descrito e das inspirações fornecidas pelo embasamento teórico que guiaram a pesquisa, cada indicador foi sendo conceituado juntamente com o reconhecimento da sua incidência na experiência concreta.

Emergiram, nesse processo interpretativo, sete indicadores qualitativos referenciais que possibilitaram dimensionar o grau de emancipação que ocorreu junto aos estudantes do projeto educativo e social em questão. Desse modo, elementos que foram se destacando nas descrições tornaram-se os potenciais indicadores para uma análise que assumiu um cunho avaliativo da prática educativa da instituição em questão, seja pela maior ou menor presença desses indicadores, ou, inclusive, a sua ausência. Segue a descrição sintética dos mesmos com uma reflexão interpretativa realizada na presente pesquisa:

Indicador 1 - Existência de um espaço de escuta na comunidade para conhecer e buscar alternativas que atendam aos seus anseios, necessidades e interesses. O processo de identificação de temas geradores constitui-se em "princípio metodológico" baseado em toda sua prática educativa (STRECK, 2014). Na experiência do projeto educativo e social estudado, percebeu-se a descontinuidade de ações referentes à abertura para o diálogo com a comunidade. Este indicador emergiu da lacuna percebida nesta prática social e que contradiz a ideia de diálogo desenvolvida por Paulo Freire. Houve indícios de que agindo assim, a ONG assumia um sério risco de não atingir o objetivo firmado por ela mesma, - de responder a demandas locais -, colocando em jogo a sua potencial contribuição na comunidade local. A incidência na esfera microssocial é condição para o seu reconhecimento e a legitimidade para atuar como força emancipadora naquele espaço (DEMO, 2002).

Indicador 2 - Presença de mediações pedagógicas com características que se aproximam da Educação Popular: desenvolvimento de um pensamento crítico, autônomo e problematizador. A Educação Popular parte dos saberes e dos conhecimentos populares que podem ser qualitativamente ampliados pela reflexão sobre os verdadeiros interesses, as necessidades e as lutas das classes populares (TORRES C., 2008). Do mesmo modo, a intencionalidade emancipadora focada no processo de transformação em todos os níveis tem sido uma das características centrais da Educação Popular. Ela é expressa por meio de práticas como: envolvimento do grupo e da comunidade local em um processo participativo, reflexão crítica sobre os problemas enfrentados localmente na sua relação com as determinações que 
advém da realidade macrossocial. Nesse sentido, preparar os sujeitos, articulando saberes populares e científicos que contribuam para os processos de conscientização, enquanto compreensão e experiência de novas maneiras de agir, pode dar coerência para uma dinâmica socioeducativa se afirmar como emancipadora.

$\mathrm{Na}$ análise documental, transpareceram elementos dos princípios da Educação Popular na fase inicial da instituição. No entanto, ao organizar seu trabalho pedagógico sob a lógica da execução de projetos financiados, a $\mathrm{ONG}$ foi levada a enfatizar a administração e a contabilidade dentro das leis vigentes, a fim de atender às expectativas de órgãos financiadores que supervalorizam metas quantitativas a serem alcançadas. Nessas condições, muitas vezes, ocorre a submissão às dinâmicas de gestão empresarial, que perde de vista a perspectiva emancipadora do trabalho com seus "atendidos". A limitada aproximação do projeto educativo e social com os pressupostos da Educação Popular, bem como a não continuidade das mesmas, acarreta a tímida presença deste indicador que consideramos central para uma educação emancipadora.

Indicador 3 - Articulação entre teoria e prática. Na metodologia de trabalho do projeto pesquisado, a partir de seus Planos de Ação, prevê-se a realização de aulas teóricas e práticas, onde cada conceito, após uma explicação, seria executado com o auxílio de exemplos dirigidos e de exercícios práticos, com o objetivo de otimizar o aprendizado. Ao perceber na observação que isso ocorria de modo muito limitado nas atividades práticas, sua proposição, na constituição dos indicadores foi imprescindível por se tratar, a nosso ver, de um elemento de essencial importância. Avalia-se, como condição para uma educação integral, a interação entre práticateoria-prática-, ou ação-reflexão-ação-, mediada por processos de aprendizagem de um ofício, de uma profissão (objetivo ao qual o projeto educativo e social se destina).

Indicador 4 - Abordagem, ao longo do curso, de questões relacionadas ao conhecimento da Economia Solidária, autogestão ou cooperativismo. A Economia Solidária caracteriza-se como uma atividade econômica que baseia sua produção, distribuição e comercialização sob uma perspectiva diferenciada, distinta da lógica das relações capitalistas de exploração do trabalho. Propõe o trabalho associado de caráter associativo e solidário de produzir e reproduzir a vida dentro das concepções e sentidos da autogestão (ADAMS, 2010). Tal perspectiva implica na superação da visão de trabalho como sinônimo de emprego, ampliando a compreensão de mercado de trabalho para mundo do trabalho. Com inspiração em teorias educacionais de cunho crítico emancipador, é de suma relevância atentar para as questões referentes aos diversos modos de trabalho nas atividades desenvolvidas ao longo do projeto estudado, visto que este se 
identifica como curso profissionalizante. Por essas razões, o presente indicador também foi elaborado a partir da sua ausência, frente às possibilidades de emancipação que poderiam ser potencializadas dentro de projetos socioeducativos.

Indicador 5 - Abordagem de questões relacionadas aos cuidados e à preservação do meio ambiente. Este indicador foi igualmente construído a partir de situações vivenciadas nos momentos de observação participante. Durante o período em que houve a imersão no campo empírico, percebeu-se como e quanto às questões relacionadas aos cuidados e à preservação do meio ambiente eram discutidas pelo Educador Social junto aos estudantes. Desse modo, decidiu-se investigar a projeção da abordagem desse tema no planejamento das ações do projeto educativo e da ONG como um todo. Contudo, não foram encontradas proposições nos documentos que comprovassem uma ação planejada, sendo esta executada por livre iniciativa e interesse do educador.

Conclui-se que uma prática educativa, que visa à transformação humana e social, precisa buscar desenvolver a compreensão da importância do cuidado e da preservação do meio ambiente, sem dissociar a dimensão ambiental da social, cultural, econômica e política. A questão ambiental tem se constituído como catalisadora de uma educação em torno de valores éticos, políticos e existenciais relacionados com a vida dos indivíduos e da sociedade. Assim, este é um indicador que, apesar de estar timidamente presente no curso pesquisado, pode ter sua discussão aprofundada com vistas a perpassar o projeto na sua totalidade.

Indicador 6 - Desenvolvimento de uma formação continuada dos educadores. Este indicador foi elaborado com base na percepção da organização e do desenvolvimento do trabalho pedagógico e observado nos momentos de inserção no campo empírico. A ONG, como um todo, sempre esteve muito envolvida e voltada para os momentos coletivos de reuniões e formações de seus educadores. Rigorosamente, em datas e períodos pré-definidos, ocorriam encontros de formação com toda a equipe da ONG (funcionários, coordenações, direção, educadores). A partir dos indícios e percebendo a atribuição da importância da formação continuada dos profissionais da educação que aparecia em diversos momentos do processo investigativo, procurou-se considerá-la como um indicador importante para avaliar a prática. Constatou-se que, em documentos da ONG, nas falas do Educador Social e em outros relatos reunidos no período de observação, eram realizadas, trimestralmente, reuniões de formação. Os desafios em torno deste indicador tem sido objeto de investimento também nos espaços de educação não escolar, sendo que uma formação continuada dificilmente se viabiliza em função 
da alta rotatividade dos educadores nas ONGs que dependem de projetos no seu processo de sustentabilidade financeira.

Indicador 7 - Acompanhamento dos estudantes egressos. A partir da análise das falas de entrevistados, apareceu o desafio da relação com egressos pelo fato de se constatar que esse acompanhamento não ocorria. A falta de informações sobre a situação dos jovens que haviam concluído o curso profissionalizante em anos anteriores levou a esse sétimo indicador. Se há uma relação de compromisso e cumplicidade construída ao longo de um processo educativo com intencionalidade emancipadora, como pode haver um corte entre estudante e instituição ao término de uma etapa de formação?

Não há informações nos documentos escritos do projeto que atestem a preocupação por um acompanhamento sistemático dos estudantes egressos. Também não foram observadas situações ou relatos que comprovassem tal prática na instituição. O Educador Social responsável pelo curso relatou que mantinha contato com alguns ex-estudantes após o período de finalização do projeto. Entretanto, tudo isso ocorre de forma não planejada e esporádica.

A pertinência desse indicador justifica-se na compreensão de que assumir o acompanhamento dos estudantes egressos constitui-se uma estratégia que, além de proporcionar a efetivação de uma prática educativa e social com os jovens participantes, poderia ser uma eficiente referência para a avaliação qualitativa dos resultados. $\mathrm{O}$ acompanhamento ao exestudante pode dimensionar o significado do projeto educativo e social em sua vida e na de sua família.

Estes sete indicadores, utilizados individual ou conjuntamente na interpretação crítica, possibilitaram compreender sentidos emancipadores presentes no trabalho educativo e social desenvolvido pela ONG, bem como a percepção dos seus limites verificada na pouca presença ou mesmo a sua ausência. Conclui-se que há muitas fragilidades e aspectos a serem reconsiderados em sua atuação, sob o risco de se estar corroborando os objetivos das políticas neoliberais. Os indicadores construídos podem contribuir para uma avaliação profunda das ações desenvolvidas por esta e outras ONGs e, assim, possibilitar o assumir com consciência o caminho e as estratégias que fortalecem uma educação emancipadora com os adolescentes e jovens envolvidos.

\section{CONCLUSÃO}


A Fenomenologia Existencial, enquanto suporte filosófico e metodológico da pesquisa, foi instrumento adequado na descrição e interpretação do fenômeno da educação não escolar. A opção pela criação de indicadores de emancipação com base na realidade estudada, em consequência, possibilitou a mediação para compreender os resultados alcançados e indicar proposições apresentadas ao final do processo de pesquisa.

$\mathrm{Na}$ escolha desse método, houve um compromisso, desde o princípio, de partir dos sentidos atribuídos pelas das pessoas implicadas na pesquisa. "A grande intuição da Fenomenologia é exatamente esta: há sentido, há sentidos, há mais sentido do que podemos dizer" (REZENDE, 1990, p. 26). Seu objetivo materializa-se pela valorização do modo de pensar, ver e viver o mundo de cada sujeito envolvido na pesquisa. O lugar de mediação dos diferentes sentidos se constitui em fenômeno onde as ambiguidades emergem e onde o mesmo fenômeno torna-se, portanto, uma estrutura que reúne homem e mundo, existência e significação no mundo vivido.

A partir da relação objetividade-subjetividade, a construção do conhecimento ocorre de modo intersubjetivo e não há como ignorar uma implicação emocional e subjetiva sempre presente na relação com o objeto de pesquisa e o modo como esta incide, em menor ou maior grau, nas interpretações feitas sobre o fenômeno. Ao invés de negá-la ou ignorá-la, o caminho é assumir a interferência subjetiva, explicitando ao máximo a condição do pesquisador e de participantes da pesquisa. Diante disso, justifica-se a utilização de mais que uma técnica para a produção de dados. Daí a definição da realização da observação participante, conectadas com a análise documental e entrevistas com pessoas e grupo.

Outro aspecto caro à pesquisa qualitativa em educação é o compromisso ético na pesquisa. Ele foi firmado, não só por meio da cuidadosa elaboração de indicadores qualitativos que pudessem interpretar os dados produzidos com comprometimento e autenticidade; mas também pela busca atenta e dedicada na apresentação de proposições válidas ao projeto educativo e social desenvolvido pela ONG. Assim, muito mais que expor resultados finais, compostos por aspectos positivos e limitações, buscou-se contribuir significativamente por meio de considerações compreensivas e indicações com base nos sete indicadores descritos.

Percebemos, ao fim da investigação, que os indicadores construídos evidenciaram limites para a emancipação de jovens e da própria comunidade. Se a emancipação passa pelo caminho do protagonismo individual e coletivo, cabe ao projeto educativo e social fortalecer as pessoas para que pensem por si mesmas e se conscientizem de sua situação e lugar no mundo. A transformação, nesse contexto, passa pelo processo solidário das relações para compreender 
que a mudança é sempre possível. Significa não seguir a lógica das políticas neoliberais, que roubam dos sujeitos os mais caros sentidos mas construir propostas distintas. Caso contrário, estaremos servindo e reforçando um modelo de assistencialismo que aliena e conduz o modo de ser, gerando dependência nos sujeitos, impedindo-os de pensar por si mesmos.

O fato de termos realizado este estudo sobre um campo empírico localizado, não permite uma generalização de conclusões estendidas para as ações do conjunto das Organizações Não Governamentais em nossa região ou país. Contudo, o mesmo poderá contribuir para a compreensão de outras realidades similares. Os indicadores de emancipação oportunizaram uma reflexão qualitativa, articulando o contexto da prática à percepção dos limites e das condições de alcance da emancipação dos jovens estudantes. Assim sendo, a construção metodológica de indicadores qualitativos para a pesquisa, brevemente apresentada no presente artigo, possui a intenção de agregar alternativas na busca por novos caminhos da pesquisa qualitativa em educação. Concluímos, igualmente, que a pesquisa qualitativa ganha com o método fenomenológico quando este busca desvendar o fenômeno social para além das aparências com destaque à compreensão dos sentidos dos fatos vividos na experiência dos sujeitos investigados.

Com singeleza, a intenção da pesquisa foi contribuir por meio da melhor compreensão e apresentação de proposições para as ONGs inseridas em um cenário repleto de contradições e ambiguidades. E, sobretudo, pela sua ampla presença junto a jovens de periferias, torna-se fundamental a contribuição da pesquisa para que elas possam de fato somar-se, juntamente com outros movimentos e organizações da sociedade, inclusive a escola, a uma construção emancipadora, transformadora da realidade social na qual estão inseridas.

\section{REFERÊNCIAS}

ADAMS, Telmo. Educação e economia popular solidária: mediações pedagógicas do trabalho associado. Aparecida - SP: Ideias e Letras, 2010.

; STRECK, Danilo. R. Pesquisa participativa, emancipação e (des)colonialidade. 1. ed. Curitiba, PR: CRV, 2014.

BRANDÃO, C. R.; STRECK, D. R. (orgs.). Pesquisa Participante: O saber da partilha. São Paulo: Brasiliense, 2006.

CABRAL, Cristiano. A. Da perca da consciência identitária camponesa à condição de situação de rua: uma leitura fenomenológica-ontológica Merleaupontyana. Universidade Federal de Mato Grosso (Dissertação - Mestrado em Educação). Cuiabá - MT, 2014, 182 p. 
CARDOSO, Roberto de Oliveira. O trabalho do antropólogo. São Paulo: Paralelo Quinze/Editora da UNESP, 1998.

DEMO, Pedro. Solidariedade como efeito de poder. São Paulo: Cortez; Instituto Paulo Freire, 2002 (Coleção Prospectiva; v.6).

FIORI, Ernani Maria. Aprender a dizer sua palavra. Prefácio. In: FREIRE, Paulo. Pedagogia do oprimido. 5. ed. Rio de Janeiro: Paz e Terra, 1978. p. 1-15.

FREIRE, Paulo. Educação como prática da liberdade. 6. ed. Rio de Janeiro: Paz e Terra. 1976.

Pedagogia do oprimido. 5. ed. Rio de Janeiro: Paz e Terra, 1978.

Ação cultural para a liberdade. 12. ed. Rio de Janeiro: Paz e Terra, 2007.

GASPARONI, Caroline Lisian. Formação profissionalizante para jovens de periferias urbanas: mediações pedagógicas emancipadoras? 146 f. 2015. Universidade do Vale do Rio dos Sinos - Dissertação de Mestrado. Programa de Pós-Graduação em Educação.

GIOVEDI, Valter Martins. A inspiração fenomenológica na concepção de ensinoaprendizagem de Paulo Freire. 2006. Pontifícia Universidade Católica de São Paulo Dissertação de Mestrado. Programa de Pós-Graduação em Educação. Orientadora: Prof. Dra. Ana Maria Saul.

HEIDEGGER, Martin. Todos nós ninguém: um enfoque fenomenológico do social. São Paulo: Moraes, 1981.

INSTITUTO PRO BONO. Manual do terceiro setor. São Paulo, 2005. http://www.abong. org.br/final/download/manualdoterceirosetor.pdf.

LAPERRIÉRE, Anne. Os critérios de cientificidade dos métodos qualitativos. In: A pesquisa qualitativa: enfoques epistemológicos e metodológicos. Tradução de Ana Cristina Nasser. Petrópolis/RJ: Vozes, 2008. p. 410-435.

MERLEAU-PONTY, Maurice. Fenomenologia da percepção. São Paulo: Martins Fontes, 199.

PASSOS, Luiz Augusto. Fenomenologia. In: STRECK, Danilo Romeu et al. Dicionário Paulo Freire. $2^{\mathrm{a}}$. Edição revista e ampliada. Belo Horizonte, MG: Autêntica, 2010. p. 185189.

REZENDE, Antônio M. Concepção fenomenológica da educação. São Paulo: Cortez: Autores Associados, 1990 (Coleção polêmicas do nosso tempo; v.38).

STRECK, Danilo R. Ecos de Angicos: Temas freirianos e a pedagogia atual. Revista ProPosições. São Paulo. Volume 25, nº 03 (75), set./dez. 2014, p.83-101. Doi:10.1590/01037307201407505 
Metodologias participativas de pesquisa e educação popular. Reflexões sobre critérios de qualidade. Interface, 2016, vol.20, n.58, p.537-547. DOI: 10.1590/180757622015.0443

TORRES C., Alfonso. T. La educación popular: trayectoria y actualidad. Bogotá: El Búho Ltda, 2008.

Data de recebimento: 03/08/2016

Data de aceite: 02/12/2016 